\title{
PENERAPAN ZACHMAN FRAMEWORK PADA ARSITEKTUR SISTEM PENGGAJIAN (STUDI KASUS: PT. ANUGERAH MITRA MULIA)
}

\author{
Mira Siti Riani \\ Payroll Division, PT. Anugerah Mitra Mulia \\ Jl. Selabintana Km 3,5 No. 41; Sukabumi 43131 \\ e-mail: mirariani01@gmail.com \\ * Korespondensi: e-mail: mirariani01@gmail.com
}

\begin{abstract}
ABSTRAK
PT. Anugrah Mitra Mulia merupakan perusahaan yang bergerak dalam bidang manufaktur. Pada bagian Keuangan, dalam mengolah data gaji pegawai baik menghitung atau membuat laporan gaji masih menggunakan Ms. Excel serta belum terintegrasi antara absensi dan penggajian sehingga kurang maksimal dalam pengolahan data. Hal ini menyebabkan dalam proses evaluasi pegawai sangat rentan terjadi kesalahan. Oleh karena itu dibutuhkan sistem informasi yang mendukung proses penggajian perusahaan. Untuk dapat merancang sistem diperlukan sebuah model architecture enterprise sistem penggajian agar dapat meminimalisir kegagalan sekaligus dapat menerapkan sistem sesuai dengan kebutuhan. Pengembangan sistem informasi menggunakan Zachman framework karena mampu memberikan perspektif-perspektif yang mampu membantu proses pengembangan sistem informasi. Rancangan sistem yang dihasilkan dalam kerangka kerja Zachman ini nantinya akan menjadi sistem informasi penggajian berbasisweb.
\end{abstract}

Kata Kunci: Manufaktur, SIM, Sistem Penggajian, Architecture Enterprise, Zachman Framework.

\begin{abstract}
PT. Anugrah Mitra Mulia is a company engaged in the manufacturing sector in Finance. In Finance, in processing employee salary data either calculating or making salary reports still using Microsoft Excel and has not been integrated between attendance and payroll so it is less than optimal in data processing. This causes the employee evaluation process is very susceptible to errors. Therefore we need an information system that supports the company's payroll process. To be able to design a system requires a payroll enterprise architecture model in order to minimize failures while implementing the system as needed. The development of information systems uses the Zachman framework because it is able to provide perspectives that can help the information system development process. The design of the system produced in the Zachman framework will later become a web based payroll information system.
\end{abstract}

Keywords:Manufacturing, SIM, Payroll System, Architecture Enterprise, Zachman Framework.

\section{PENDAHULUAN}

\subsection{Latar Belakang}

PT. AMM merupakan perusahaan yang berkecimpung dibidang manufaktur yang sudah beroperasi lebih dari 5 tahun. Namun dalam pelaksanaa nya masih belum memiliki pendefinisian yang jelas mengenai arsitektur data, proses, dan jaringan dalam sistem informasi. Terutama dalam proses peng gajian. Saat ini dalam sistem penggajian masih menggunakan perogram alat bantu Ms. Excel, dimana perhitungan gaji dan penyimpanan data-data tersebut tidak disimpan ke dalam database dan menye babkan suatu saat file atau beberapa dokumen yang direkap bisa terhapus atau hilang. Masalah terse but tidak akan terjadi jika PT. AMM memiliki arsitektur aplikasi sistem penggajian.

Masalah tersebut di atas tidak akan terjadi jika PT. AMM memiliki arsitektur aplikasi sistem peng gajian. Arsitektur aplikasi sistem informasi sendiri bisa dilihat dari aspek dan Perspektif yaitumenggunakan Zachman Framework. Arsitektur aplikasi sistem informasi perusahaan ini diguna kan untuk membuat strategi implementasi sistem informasi yang baik. Arsitektur aplikasi sistem in formasi Zachman Framework memperhatikan suatu sistem informasi dilihat dari enam aspek utama, 
yaitu: Data, Function, Network, People, Motivation, dan Time serta 6 (enam) Perspektif berbeda, yai tu: Planner, Owner, Designer, Contractor, Subcontractor, dan Functioning Enterprise.

Dalam penelitian ini penulis akan membahas perancangan arsitektur enterprise untuk menghasi lkan prototype aplikasi teknologi informasi khususnya pada sistem informasi penggajian, yang selaras dengan kebutuhan bisnis yang sedang berjalan di PT. AMM sehingga dapat membantu sebuah per usahaan dalam mempercepat proses menuju sasaran dan tujuan yang diinginkan

\subsection{Rumusan Masalah}

1. Bagaimana merancang sebuah arsitektur aplikasi yang mampu menangani proses absensi karya wan untuk keperluanpenggajian.

2. Bagaimana membuat suatu sistem yang mampu melakukan proses penghitungan data penggajian bagi masing-masing karyawan dengan waktu yang optimal.

3. Bagaimana membuat suatu aplikasi yang dapat menangani proses penggajian yang ada pada PT. AMM mulai dari penentuan gaji pokok setiap karyawan, jenis tunjangan, dan parameter lain yang mempengaruhinya

\subsection{Batasan Masalah}

1. Perancangan Enterprise architecture melingkupi arsitektur data, arsitektur aplikasi dan arsitektur teknologi.

2. Sumber data yang digunakan untuk penelitian ini berasal dari lingkungan PT.AMM.

3. Data didapatkan melalui proses observasi, wawancara, dan penyebaran angket dengan pihak pru sahaan.

\subsection{Tujuan Penelitian}

1. Membuat sebuah model aplikasi yang menangani proses absensi karyawan untuk keperluan penggajian.

2. Membuat sebuah sistem yang mampu melakukan proses penggajian bagi seluruh karyawan dengan waktu yang optima.

3. Merancang dan membangun sebuah model perangkat lunak yang mampu menangani proses peng gajian pada PT AMM, mulai dari penentuan gaji pokok setiap karyawan, jenis tunjangan, dan pa rameter lain yang mempengaruhinya.

\subsection{Manfaat Penelitian}

Dengan penelitian ini, penulis berharap untuk meminimumkan konflik-konlik dalam proses absensi dan penggajian yang dapat memperlambat proses yang ada pada perusahaan. Dengan rancan gan aplikasi yang dibangun diharapkan proses penggajian yang ada pada PT. AMM akan dapat dilakukan lebih cepat dan sesuai dengan kebutuhan yang ada.

\section{TINJAUAN PUSTAKA}

\subsection{Definisi Gaji}

Penggajian adalah suatu penerimaan sebagai imbalan dari pengusaha kepada karyawan untuk suatu pekerajaan atau jasa yang telah atau dilakukan dan dinyatakan atau dinilai dalam bentuk uang yang ditetapkan atas dasar suatu persetujuan atau peraturan. perundang-undangan serta dibayarkan atas da sarsuatu perjanjian kerja antara pengusaha dengan karyawan termasuk tunjangan, baik untuk karya wan itu sendiri maupun untuk keluarga [1].

\subsection{Definisi Data}

Data merupakan bentuk jamak dari bentuk tunggal data item. Data adalah fakta-fakta, sim bol/karekter, data mentah atau observasi yang menggambarkan suatu fenomena tertentu [2]. 


\subsection{Definisi Pengelolaan data}

Pengelolaan data adalah segala macam pengelolaan terhadap data atau kombinasi-kombinasi dari berbagai macam pengelolaan terhadap data untuk membuat data itu berguna sesuai dengan hasil yang diinginkan dapat segera dipakai [3].

\subsection{Sistem Informasi Manajemen}

Sistem informasi manajemen adalah sebuah sistem manusia/mesin yang terpadu (integrated) untuk menyajikan informasi guna mendukung fungsi operasi, manajemen, dan pengambilan keputusan da lam sebuah organisasi [4].

\subsection{Perangkat Lunak Pendukung}

Berikut merupakan beberapa perangkat lunak pendukung yang digunakan untuk pengembangan sistem penggajian:

1. PHP.

2. Xampp

3. MySQL

\subsection{Enterprise Arsitektur (EA)}

EA adalah penjelasan bagaimana sebuah organisasi merancang suatu sistem untuk mendu kung kebutuhan bisnis dan teknologi dalam mewujudkan misi dan visi serta pencapaian hasil yang telah ditargetkan. Munculnya EA diawali dari dua hal [5], yaitu:

1. Sistem yang rumit, dimana organisasi harus mengeluarkan biaya yang cukup besar untuk merancang atau mengembangkan sistem yang dimiliki.

2. Keselarasan bisnis dengan teknologi, dimana banyaknya organisasi yang mengalami kesulitan dalam menyelaraskan kebutuhan bisnis dengan teknologi.

EA memiliki tiga komponen utama yaitu arsitektur bisnis, arsitektur sistem informasi (terbagi menjadi arsitektur data dan aplikasi) dan arsitektur teknologi [6].

\subsection{EA Framework}

Framework didefinisikan sebagai kunci pemahaman atas EA yang berperan sebagai suatu struktur logis dalam mengklasifikasikan informasi yang kompleks [7].

Menggunakan sebuah framework untuk mengembangkan EA maka, perlu diperhatikan kriteriakriteria apa saja yang dipenuhi oleh framework tersebut. Adapun beberapa kriteria yang dijadikan sebagai pertimbangan dalam memilih framework [8], yaitu:

1. Taxonomy completeness, mengacu pada seberapa baik sebuah framework mengklasifikasikan arsitektur aplikasi.

2. Process completeness, mengacu pada bagaimana sebuah framework memberikan panduan dalam bentuk proses (langkah-langkah) untuk menciptakan suatu EA.

3. Practice guidance, mengacu pada seberapa banyak sebuah framework membantu mindset pengguna (easy using) didalam organisasi untuk memahami pengembangan EA.

4. Maturity model, mengacu pada seberapa banyak sebuah framework memberikan panduan dalam memberi penilaian atau evaluasi terhadap organisasi yang menggunakan EA.

5. Governance guidance, mengacu pada sejauh mana sebuah framework membantu memberikan pemahaman serta membuat model tata kelola yang efektif untuk EA.

6. Partioning guidance, mengacu pada seberapa baik sebuah framework akan membimbing partisi otonomi yang efektif pada perusahaan sehingga menjadi sebuah pendekatan penting untuk mengelola kompleksitas.

7. Vendor neutrality, mengacu pada seberapa besar kemungkinan EA untuk bergantung pada sebuah organisasi konsultasi khusus ketika menggunakan framework tersebut.

8. Information availability, mengacu pada seberapa besar sebuah framework dalam menghasilkan kuantitas dan kualitas informasi.

9. Time is value, megacu pada seberapa lama sebuah framework memerlukan waktu yang digunakan untuk membangun solusi yang memberikan nilai bisnis.

Ada berbagai framework yang bisa digunakan dalam mengembangkan EA. Menurut hasil survey yang dilakukan IFEAD (Institute for Enterprise Architecture Development), mengemukakan perban- 
dingan jenis-jenis framework yang digunakan dalam organisasi.

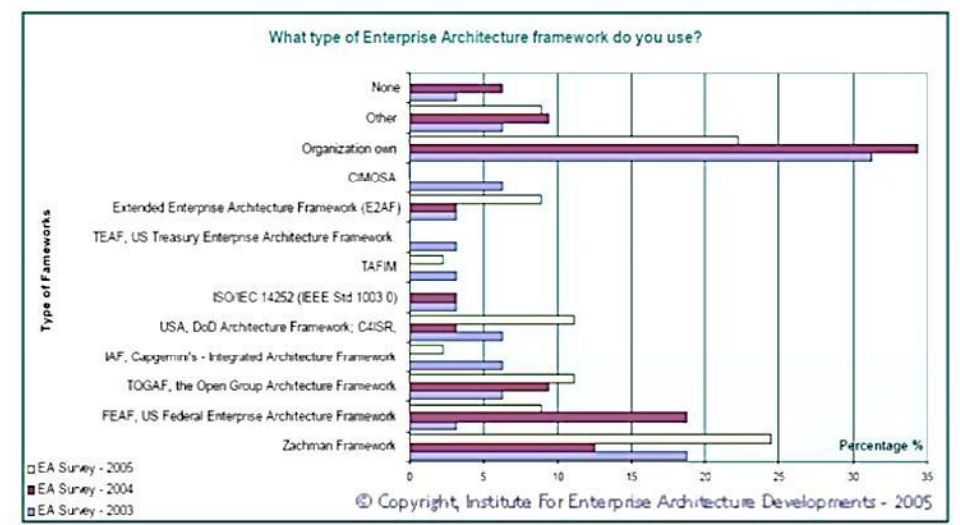

Gambar 1. Survey Penggunaan Framework Periode 2003-2005 Oleh IFEAD

Pada tahun 2005, penggunaan Zachman Framework mengalami suatu kemajuan yang pesat dibandingkan pada penggunaan tahun sebelumnya. Penggunaan TOGAF juga mengalami kemajuan tetapi, tidak banyak seperti Zachman Framework. Sementara itu, penggunaan FEAF mengalami penurunan drastis dibandingkan tahun sebelumnya. TEAF dan beberapa framework lainnya tidak dipresentasikan dalam survey penggunaan framework pada tahun 2005.

\subsection{Zachman Framework}

Kerangka kerja Zachman (Zachman Framework) yang diperkenalkan pertama kali oleh John Zachman pada tahun 1987 yang awalnya berupa struktur matriks 6x3, kemudian diperluas dan diformulasikan oleh Sowa dan Zachman pada tahun 1992 menjadi matriks 6x6. Setiap model kerangka kerja mendefinisikan entitas-entitas arsitektur dalam baris-baris dan atribut untuk setiap entitas ke dalam kolom-kolom. Kerangka kerja Zachman bukan suatu metodologi untuk mengembangkan enterprise architecture, akan tetapi kerangka kerja Zachman merupakan struktur dimana suatu metodologi diproses [9]. Berikut Zachman Framework untuk arsitektur enterprise yang terdiri dari 6 (enam) kolom dan 6 (enam) baris:

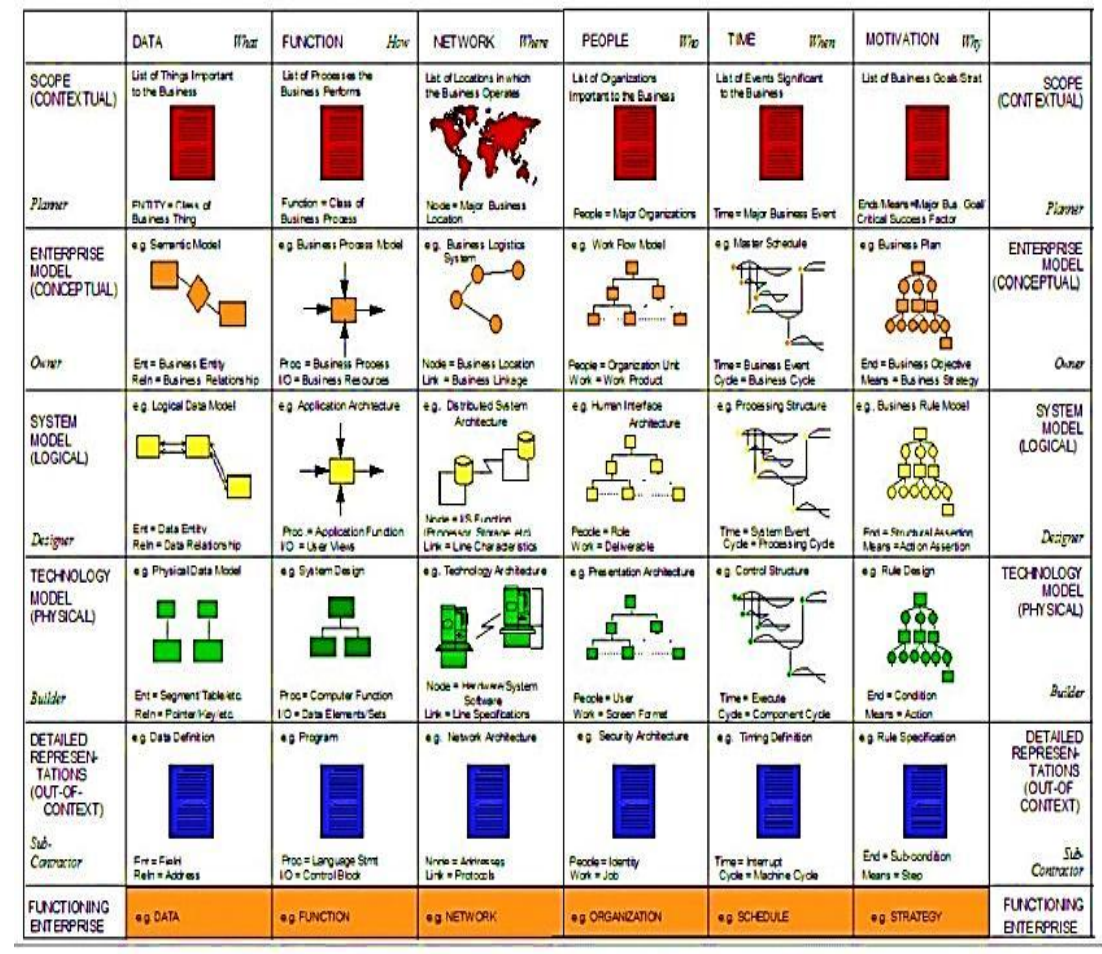

Gambar 2. Zachman Framework

Secara umum tiap kolom dalam kerangka kerja Zachman diuraikan lebih lanjut sebagai berikut: 
1. Data (What): Berfokus pada relasi entitas. Kolom ini menggambarkan kebutuhan enterprise akan informasi yang terbuat dari data.

2. Fungsi (How): Berfokus pada proses dan fungsi termasuk input dan output yang dihasilkan. Kolom ini memberikan uraian fungsional atas komponen sistem informasi.

3. Jaringan (Where) : Berfokus pada node-node dan link-link. Kolom ini memberikan gambaran mengenai arus informasi dan pekerjan dalam enterprise.

4. Orang (Who) : Berfokus pada kontributor (agen) pekerjaan yang terkait. Kolom ini berhubungan dengan alokasi pekerjaan dan struktur tanggung jawab dan otoritas dalam enterprise.

5. Waktu (When): Berfokus pada waktu dan siklus. Kolom ini digunakan untuk mendesain merancang relasi dari serangkaian kejadian (event toevent) yang menetapkan kriteria kinerja dan tingkatan kuantitatif untuk sumber daya enterprise

6. Motivasi (Why) : Berfokus pada sasaran dan tujuan (ends) serta strategi atau metode (means) Setiap baris pada kerangka kerja Zachman mewakili perspektif yang berbeda dan unik yaitu [10]:

1. Perspektif Perencana (Tujuan/Cakupan), yaitu menetapkan gambaran umum sistem informasi, latar belakang dan tujuan enterprise.

2. Perspektif Pemilik (Model Bisnis), yaitu menetapkan model-model konseptual dari enterprise dan bagaimana model enterprise digunakan.

3. Perspektif Arsitek (Model Sistem Informasi), yaitu menetapkan modelmodel sistem informasi sekaligus menjembatani hal-hal yang diinginkan pemilik dan hal-hal yang dapat direalisasikan secara teknikal dan bisnis.

4. Perspektif Builder (Model Teknologi), yaitu mengelola proses untuk pembuatan komponenkomponen sistem informasi yang membutuhkan pemahaman yang cermat dari spesifikasi arsitek untuk sistem.

5. Perspektif Subkontraktor (Representasi Detail), yaitu membangun bagian spesifik dari produk yang menghasilkan komponen-komponen yang sesuai dengan spesifikasi yang disediakan.

6. Perspektif Pengguna (Fungsi Sistem), yaitu merepresentasikan antarmuka dan fungsionalitas dari produk akhir yang merupakan prodek dari semua perencanaan, perancangan dan aktivitas-aktivitas pengembangan yang berjalan sebelumnya.

\subsection{UML}

Unified Modeling Language (UML) adalah sebuah bahasa pemodelan yang digunakan untuk me nentukan atau mendeskripsikan sebuah sistem software berdasarkan objek-objek yang ada di sistem tersebut. UML tidak menentukan metode apa yang harus digunakan dalam mengembangkan suatu sistem, namun hanya menentukan notasi-notasi standar yang biasa digunakan untuk object modeling. Berikut adalah empat macam UML yang umum digunakan pada saat pengembangan sebuah software atau website [11]:

1. Use Case Diagram.

3. Class Diagram.

4. Sequence Diagram.

5. Activity Diagram

\section{METODE PENELITIAN}

Berikut merupakan gambaran mengenai kerangka penelitian yang dilakuakan terhadap penerapan sistem pengggjian yang mengacu pada stuktur dasar dari metode Zachman Framework. 


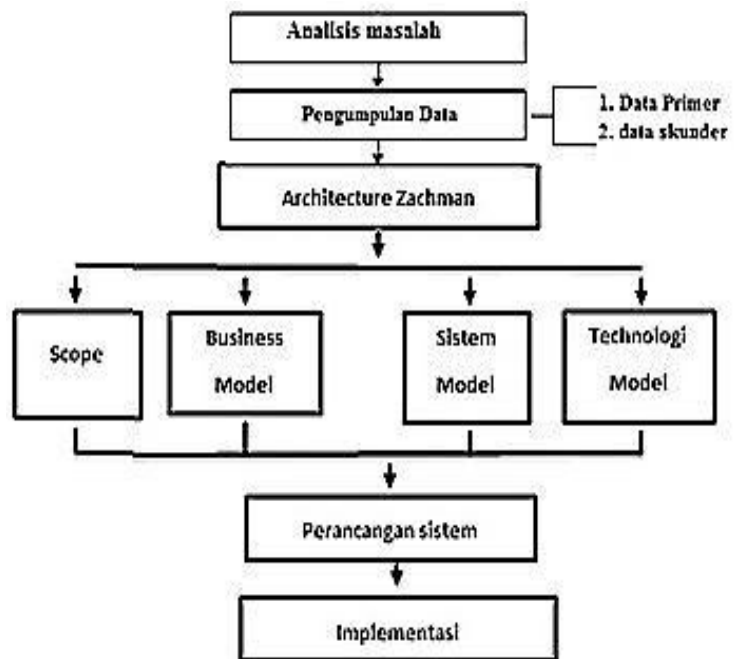

Gambar 3. Metode Penelitian

Adapun tahapan-tahapan metodologi penelitian yang akan dijelaskan pada uraian dibawah ini.

\subsection{Metode Pengumpulan Data}

Metode yang digunakan untuk mengumpulkan data dan informasi yaitu dengan melakukan obser vasi langsung ke objek penelitian, dengan cara wawancara kepada pengguna sistem dan mengumpulkan dokumen-dokumen yang terkait dengan proses pengelolaan data penggajian.

\subsection{Sumber data}

Data terbagi atas dua jenis yaitu data primer dan data sekunder.

\subsection{Pengujian Teknis}

Adapun pengujian Black Box mencakup beberapa pengujian, yaitu:

1. Pengujian Fungsional (FunctionalTesting), Pengujian fungsional meliputi seberapa baik sistem me laksanakan fungsinya, termasuk perintah-perintah pengguna, manipulasi data, pencarian dan pros es bisnis, pengguna layar dan integrasi.

2. Pengujian Usabilitas (usabilitytesting), Usability berasal dari kata Usable yang secara umum berar ti dapat digunakan dengan baik

\subsection{Metode Analisis Masalah}

Data dan informasi yang diperoleh dari hasil observasi, wawancara maupun kuesioner, dianalisis untuk kemudian dituangkan dalam matrik dua dimensi dari Zachman framework agar diperoleh gambaran sistem yang akan dibangun sesuai dengan kebutuhan enterprise architecture, untuk mencapai enterprise tersebut.

Penelitian ini menggunakan sudut pandang Perspektif Planner (scope), owner (business model), designer (system model) dan builder (technology model) dengan masing-masing kolom yang terdiri dari Data (What), Proses (How), Lokasi (Where), Orang (Who), dan Waktu (When).

\subsection{Hasil Analisis}

\section{HASIL DAN PEMBAHASAN}

Hasil analisis kebutuhan terhadap sistem informasi penggajian, dilakukan melalui proses penyebaran kuisioner dengan sebaran data sebagai berikut: 
Tabel 1. Sebaran Responden Kuisioner

\begin{tabular}{|c|c|c|c|}
\hline \multirow{4}{*}{ Klasifikasi Responden } \\
\hline \multirow{3}{*}{ Jenis Kelamin } & Kategori & Jumlah & Total \\
\cline { 2 - 4 } & Laki-laki & 13 & \\
\cline { 2 - 4 } & Perempuan & 37 & 50 \\
\hline \multirow{7}{*}{ Jabatan } & Manajer & 1 & \\
\cline { 2 - 4 } & HRD & 4 & \\
\cline { 2 - 4 } & Staf Produksi & 16 & \\
\cline { 2 - 4 } & Karyawan & 29 & 50 \\
\hline
\end{tabular}

Metode kuisioner yang dilakukan adalah metode tertutup, yang dimana responden diminta menja wab pertanyaan dan menjawab dengan memilih dari sejumlah alternatif yang diberikan.Berikut adalah hasil dari rekapan data responden:

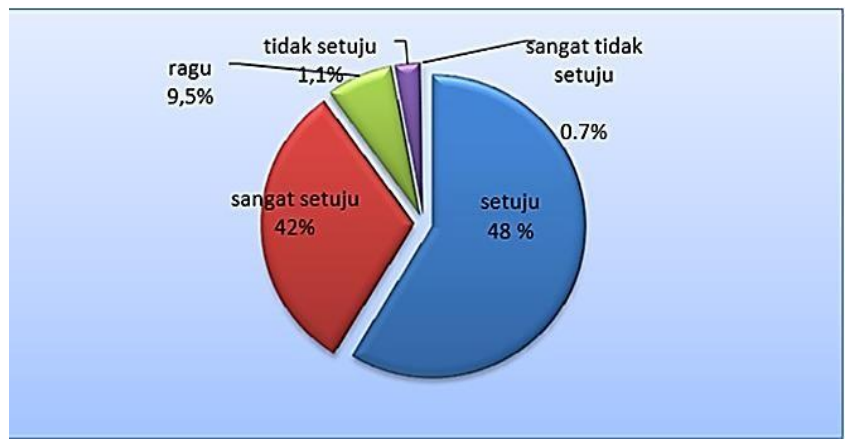

Gambar 4. Persentase hasil rekapan data kuesioner variabel X

Dari hasil rekapitulasi jawaban responden dengan jawaban tertinggi yaitu menjawab sangat setuju $42 \%$, responden menjawab setuju $48 \%$, responden menjawab ragu-ragu $11.3 \%$, responden menjawab tidak setuju dan 3\%, dan responden yang menjawab sangat tidak setuju $0.7 \%$. Sebagianbesarresponden menjawab setuju sebesar $90 \%$ responden menjawab sangat setuju dari $(36.2 \%$ responden setuju + 48.9\% responden sangat setuju) bahwa pola pengembangan Zachman framework menggunakan akses Web yang diterapkan pada pembuatan sistem penggajian perusahaan berdampak sangat baik.

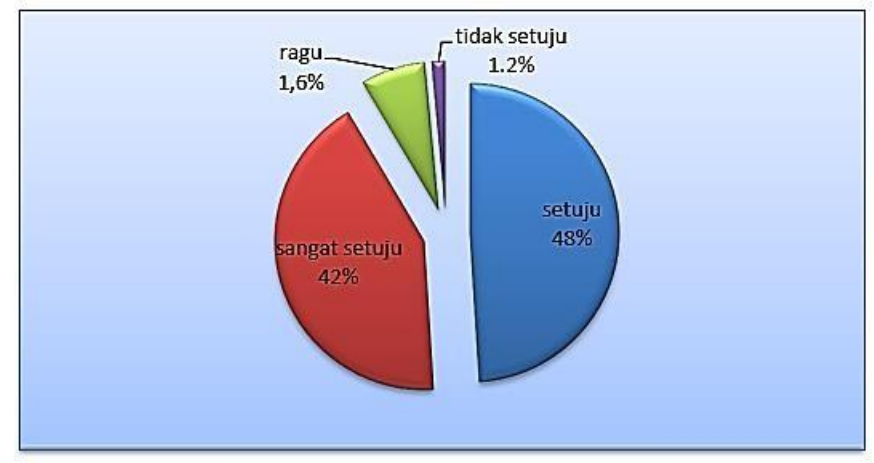

Gambar 5. Persentase hasil rekapan data kuesioner variabel Y

Dari rekapitulasi jawaban responden, jawaban tertinggi $48.8 \%$ responden menjawab puas dan $43.3 \%$ responden menjawab sangat puas, total secara keseluruhan responden menjawab puas sebesar $81 \%$, bahwa sistem penggajian yang diterapkan pada perusahaan hal baik itu tergambar dari responden yang menjawab atas pengelolaan data sistem penggajian. 
Tabel 2. Analisis Korelasi

\begin{tabular}{|c|c|c|c|c|}
\hline \multicolumn{5}{|c|}{ Correlations } \\
\hline & & & $\mathrm{x}$ & y \\
\hline \multirow{6}{*}{$\begin{array}{l}\text { Spearman's } \\
\text { rho }\end{array}$} & Framework & Correlation Coefficient & 1.000 &, $509^{\prime \prime}$ \\
\hline & Zachman & Sig. (2-tailed) & & .000 \\
\hline & & $\mathrm{N}$ & 50 & 50 \\
\hline & Sistem & Correlation Coefficient & $509^{* *}$ & 1.000 \\
\hline & Penggajian & Sig. (2-tailed) & .000 & \\
\hline & & $\mathrm{N}$ & 50 & 50 \\
\hline
\end{tabular}

Berdasarkan hasil analisis dengan uji rho spearman's seperti pada tabel di atas maka dapat dilihat bahwa nilai korelasi antara Zachman Framework (Variabel X) yang di implementasikan pada Sistem Penggajian (Variabel Y) diperoleh angka koefisien korelasi sebesar $r=0.509$, nilai ini berada diantara nilai $0,51-0,75$, yang artinya tingkat kekuatan hubungan (korelasi).adalah cukup kuat, angka koefisien korelasi bernilai positif $=0.512$ sehingga hubungan kedua variabel bersifat searah(jenis hubungan searah), artinya jika penerapan Zachman Framework dengan Web yang di implementasikan pada sistem penggjian semakin baik maka akan berdampak baik pada sistem penggjian yang ada di perusahaan.

\subsection{Pembahasan Tabel Zachman}

\section{Kolom What}

Menjelaskan tentang data dari sudut pandang planner, owner, designer, dan builder. Selengkapnya dapat dilihat pada tabel dibawah ini:

Tabel 3. Kolom what dalam berbagai sudut pandang

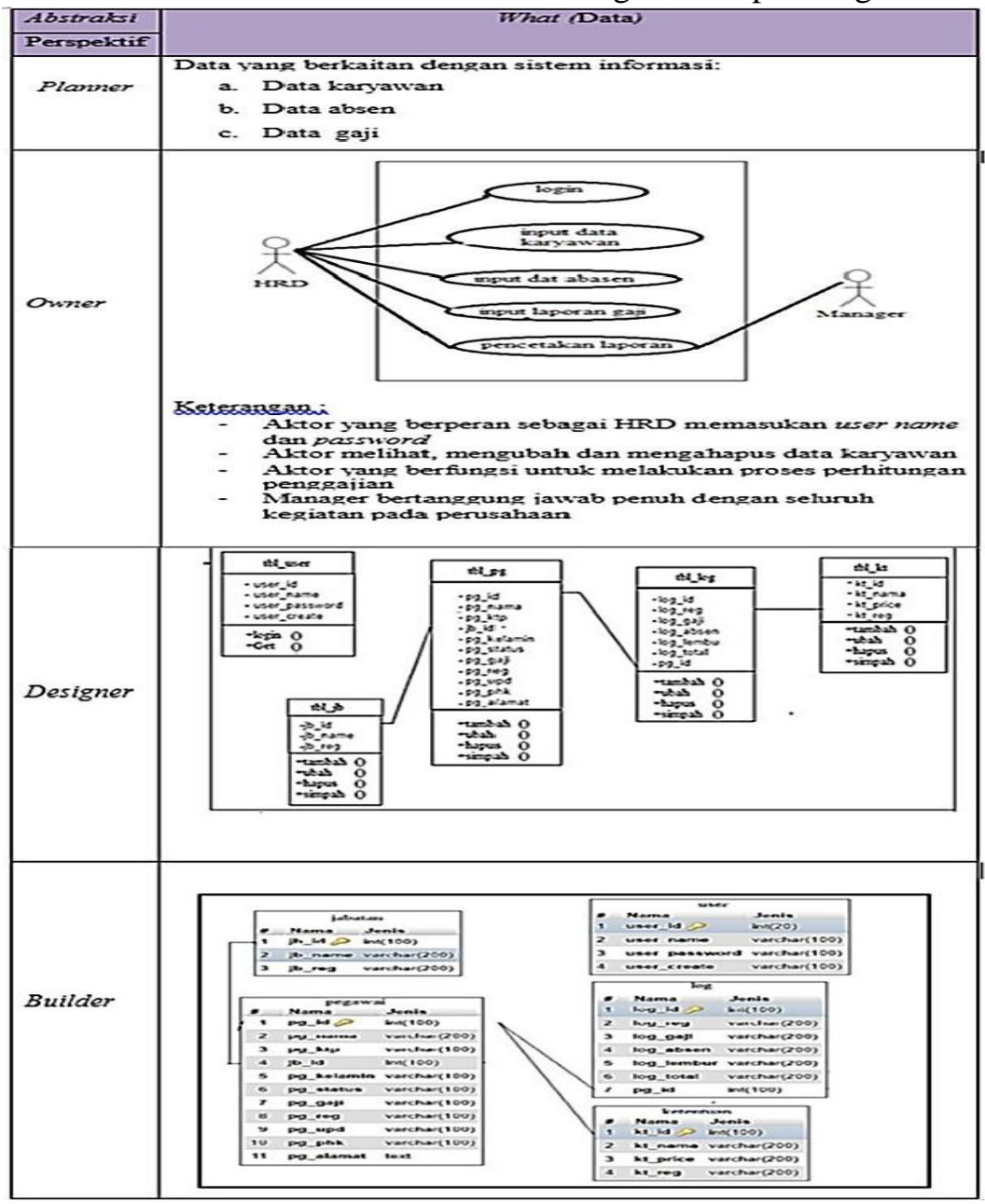


JURSISTEKNI (Jurnal Sistem Informasi dan Teknologi Informasi) Vol 2, No.1, Januari 2020: Hal. 19 -32 ISSN. P: 2715-1875, E: 2715-1883

\section{Kolom How}

Kolom ini membahas tentang proses-proses yang terjadi pada proses penggajian dilihat dari sudut pandang planner, owner, designer, dan builder. Selengkapnya dapat dilihat pada tabel di bawah ini:

Tabel 4. Kolom how dalam berbagai sudut pandang

\begin{tabular}{|c|c|}
\hline Abstraksi & How (Proses) \\
\hline Perspektif & \\
\hline Planner & $\begin{array}{l}\text { - Peroses input data karyawan. } \\
\text { - Data absen dan data upah } \\
\text { - Data pelaporan }\end{array}$ \\
\hline Owner & $\begin{array}{l}\text { - } \quad \text { Karyawan melakukan absen } \\
\text { - } \quad \text { HRD/Satff Personalias memeriksa data absen } \\
\text { - } \quad \text { Penghitungan (denda +upah)karyawan. } \\
\text { - Pelaporan ke pihak manager }\end{array}$ \\
\hline Designer & $\begin{array}{l}\text { Diagram aktivitas prilaku sistem dilihat pada gambar aktivity } \\
\text { diagram. }\end{array}$ \\
\hline Builder & $\begin{array}{l}\text { Pemodelan proses yang terjadi di dalam sistem informasi ke dalam } \\
\text { sequence diagram dilihat pada gambar. }\end{array}$ \\
\hline
\end{tabular}

\section{Kolom Where}

Kolom ini membahas tentang lokasi bisnis utama tempat sistem informasi berada beserta infra struktur dan konfigurasinya. Detailnya dapat dilihat pada tabel berikutini:

Tabel 5. Kolom where dalam berbagai

\begin{tabular}{|l|l|}
\hline Abstraksi & \multicolumn{2}{|}{ Where (Lokasi) } \\
\cline { 1 - 1 } Perspektif & \\
\hline Plammer & PT. ANUGRAH MITRA MULIA \\
\hline Onwer & Peta jaringan yang ada di ruangan HRD \\
\hline Designer & Peta jaringan yang diusulkan \\
\hline Builder & Peta jaringan pengelolaan penggajian \\
\hline
\end{tabular}

\section{Kolom Who}

Kolom ini membahas tentang sumber daya manusia yang berperan penting dalam proses perse diaan barang dan produktifitas yang optimal seperti penjelasan berikut:

Tabel 6. Kolom who dalam berbagai sudut pandang

\begin{tabular}{|c|c|}
\hline Abstraksi & Who (Orang) \\
\hline Perspektif & \\
\hline Planner & $\begin{array}{l}\text { Orang-orang yang berperan penting dalam proses tersebut } \\
\text { - Departement } \mathrm{HRD}\end{array}$ \\
\hline Ormer & $\begin{array}{l}\text { Daftar unit orang-orang internal atau yang terkait: } \\
\text { - Seluruh karyawan yang ada dilngkungan prusahaan }\end{array}$ \\
\hline Designer & $\begin{array}{l}\text { Orang-orang yang ditugaskan untuk pembangunan dan mengelola } \\
\text { sistem informasi data penggajian }\end{array}$ \\
\hline Builder & $\begin{array}{l}\text { Gambaran antar muka aplikasi sistem penggajian yang akan } \\
\text { dibangun } \\
\text { Dilihat pada gambar perancangan user interface }\end{array}$ \\
\hline
\end{tabular}


JURSISTEKNI (Jurnal Sistem Informasi dan Teknologi Informasi) Vol 2, No.1, Januari 2020: Hal. 19 -32 ISSN. P: 2715-1875, E: 2715-1883

\section{Kolom When}

Kolom ini membahas tentang kejadian atau kegiatan beserta jadwalnya. Kegiatan utama yang akan dibahas adalah berkaitan dengan kegiatan penggajian perusahaan penjelasan dapat dilihat pada tabel berikut:

Tabel 7. Kolom when dalam berbagai sudut pandang

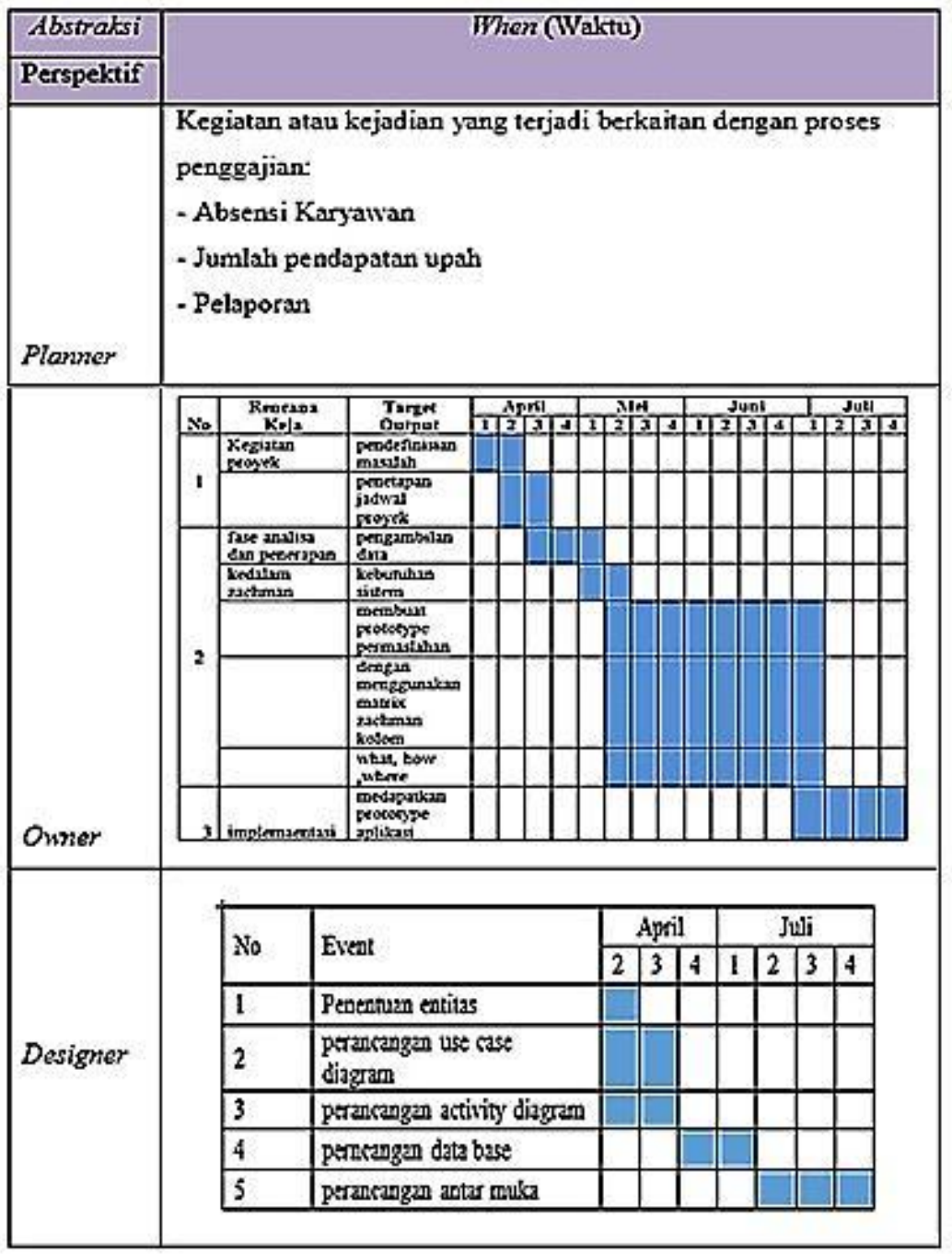

\subsection{Implementasi Sistem Penggajian}

a) Halaman Login

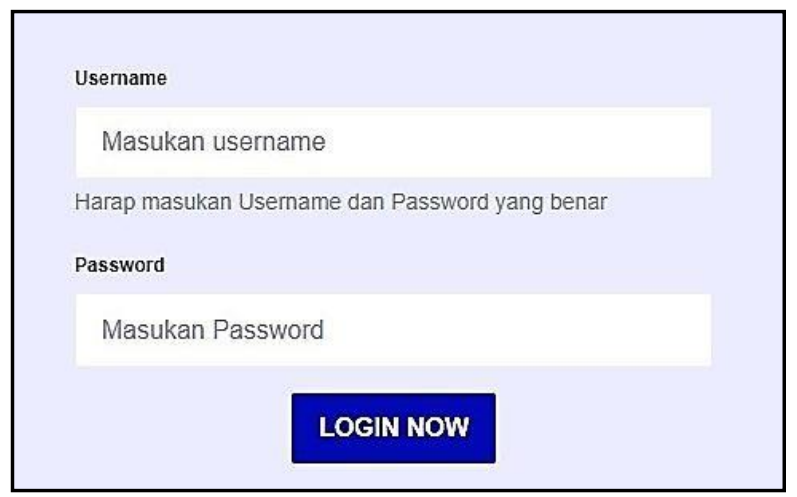

Gambar 6. Halaman Login 
Halaman awal dari system penggajian langsung masuk ke halaman ke halaman Login yang dimana setiap aktor memiliki username dan password.

b) HalamanAdmin; Menu User ini adalah menu menampilkan user aplikasi.

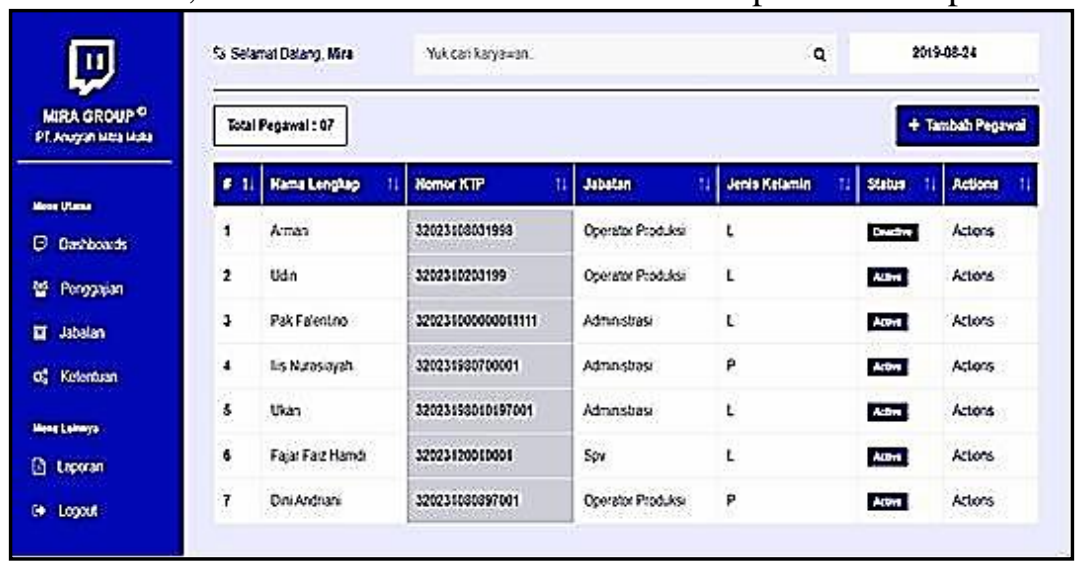

Gambar 7. Halaman Admin

c) Tampilan Input Data; Menu Bagian ini adalah menu untuk menambah data pegawai.

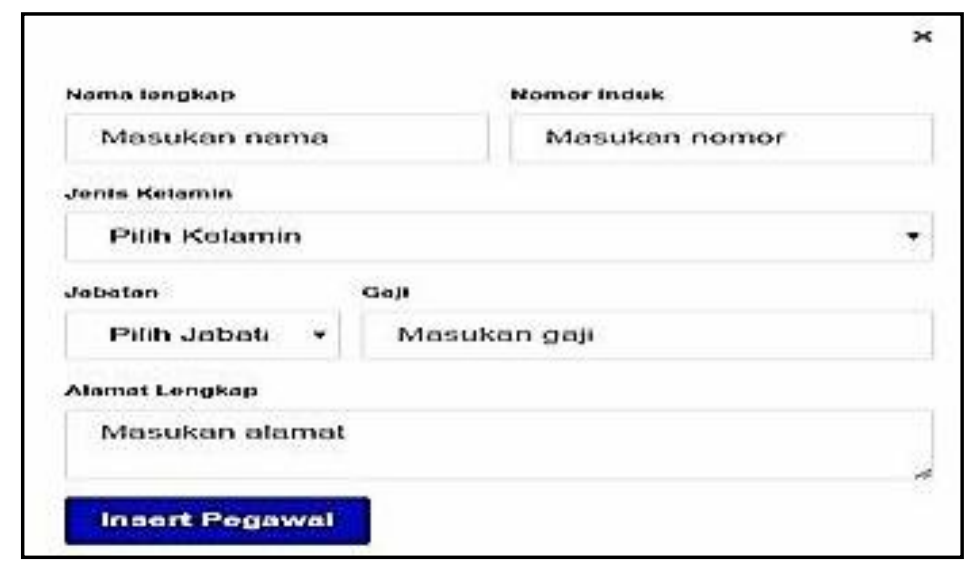

Gambar 8. Halaman Input Data

d) Halaman Jabatan

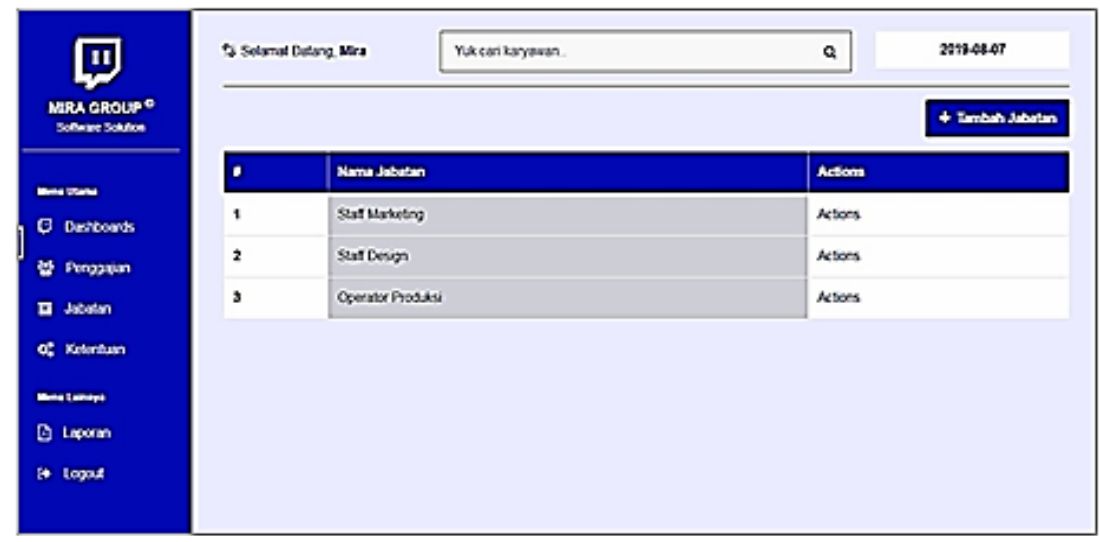

Gambar 9. Halaman Jabatan

e) Halaman Ketentuan Karyawan 


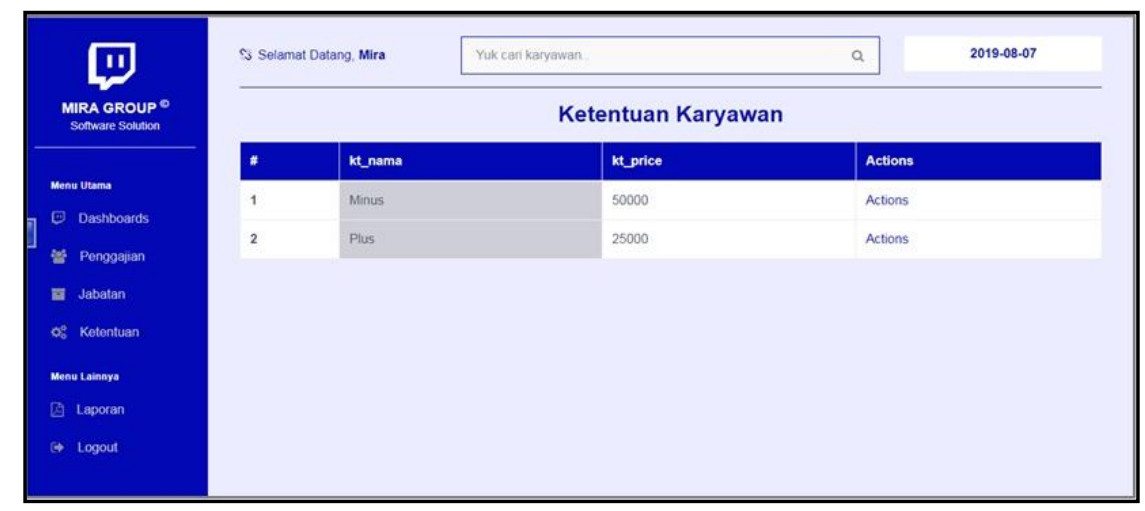

Gambar 10. Halaman Ketentuan Karyawan

\subsection{Pengujian sistem menggunakan Black Box Testing pada aplikasi penggajian}

Untuk indikator-indikator pada pengujian fungsional ini, aplikasi diuji dengan menguji serangkaian fungsi pada Aplikasi Sistem Penggajian, untuk pengujian penelitian menggunakan test case pada ketersediaan aplikasi untuk memenuhi fungsional dari sistem pengolahaan data penggajian yang didefinisikan pada tabel-tabel berikut ini:

Tabel 8. Testing Funtional Indikator Suitability

\begin{tabular}{|c|c|c|c|c|}
\hline Fungsi & Pengisian form & $\begin{array}{l}\text { Hasil Yang Di- } \\
\text { harapkan }\end{array}$ & $\begin{array}{c}\text { Pengamatan } \\
\text { Hasil Pengujian }\end{array}$ & Keterangan \\
\hline $\begin{array}{l}\text { Untuk melaku- } \\
\text { kan Login }\end{array}$ & $\begin{array}{l}\text { Masukkan user- } \\
\text { name dan pass- } \\
\text { word yang sesuai. }\end{array}$ & $\begin{array}{l}\text { Sesuai kebutuhan } \\
\text { user/pengguna. }\end{array}$ & $\begin{array}{l}\text { Sesuai dengan } \\
\text { kebutuhan peng- } \\
\text { guna. }\end{array}$ & Valid \\
\hline $\begin{array}{l}\text { Untuk melaku- } \\
\text { kan pencarian }\end{array}$ & $\begin{array}{l}\text { Mengisi form } \\
\text { yang tersedia }\end{array}$ & $\begin{array}{l}\text { Sesuai kebutuhan } \\
\text { user/pengguna }\end{array}$ & $\begin{array}{l}\text { Sesuai dengan } \\
\text { kebutuhan peng- } \\
\text { guna. }\end{array}$ & Valid \\
\hline $\begin{array}{l}\text { Untuk melaku- } \\
\text { kan input data }\end{array}$ & $\begin{array}{l}\text { Mengisi form } \\
\text { data karyawan }\end{array}$ & $\begin{array}{l}\text { Sesuai kebutuhan } \\
\text { user/pengguna }\end{array}$ & $\begin{array}{l}\text { Sesuai dengan } \\
\text { kebutuhan peng- } \\
\text { guna. }\end{array}$ & Valid \\
\hline $\begin{array}{l}\text { Untuk melaku- } \\
\text { kan hapus data }\end{array}$ & $\begin{array}{l}\text { Mengisi form } \\
\text { yang tersedia }\end{array}$ & $\begin{array}{l}\text { Sesuai kebutuhan } \\
\text { user/pengguna }\end{array}$ & $\begin{array}{l}\text { Sesuai dengan } \\
\text { kebutuhan peng- } \\
\text { guna. }\end{array}$ & Valid \\
\hline $\begin{array}{l}\text { Untuk menam- } \\
\text { bah kan da- } \\
\text { ta/ubah data }\end{array}$ & $\begin{array}{l}\text { Mengisi form } \\
\text { yang tersedia }\end{array}$ & $\begin{array}{l}\text { Sesuai kebutuhan } \\
\text { user/pengguna }\end{array}$ & $\begin{array}{l}\text { Sesuai dengan } \\
\text { kebutuhan peng- } \\
\text { guna. }\end{array}$ & Valid \\
\hline
\end{tabular}


Tabel 9. Funtional Testing Indikator Accuracy

\begin{tabular}{|l|l|l|l|l|}
\hline Fungsi & Pengisian form & $\begin{array}{l}\text { Hasil Yang } \\
\text { Diharapkan }\end{array}$ & $\begin{array}{l}\text { Pengamatan Hasil } \\
\text { Pengujian }\end{array}$ & Keterangan \\
\hline $\begin{array}{l}\text { Menambah- } \\
\text { kan data } \\
\text { upah }\end{array}$ & $\begin{array}{l}\text { Memilih menam- } \\
\text { bah kategori na- } \\
\text { ma karyawan }\end{array}$ & $\begin{array}{l}\text { Sesuai kebu- } \\
\text { tuhan peng- } \\
\text { guna }\end{array}$ & $\begin{array}{l}\text { Hasil setelah peng- } \\
\text { guna mengisi adalah } \\
\text { sesuai yang di ha- } \\
\text { rapkan }\end{array}$ & Valid \\
& & & \\
\hline
\end{tabular}

Tabel 10. Funtional Testing Indikator Security

\begin{tabular}{|l|l|l|l|l|}
\hline Fungsi & $\begin{array}{l}\text { Pengisian } \\
\text { form }\end{array}$ & $\begin{array}{l}\text { Hasil Yang Di- } \\
\text { harapkan }\end{array}$ & $\begin{array}{l}\text { Pengamatan Hasil } \\
\text { Pengujian }\end{array}$ & Keterangan \\
\hline $\begin{array}{l}\text { Keamanan } \\
\text { akses in- } \\
\text { formasi }\end{array}$ & Mengisi form & $\begin{array}{l}\text { Sesuai kebutu- } \\
\text { hegin sesuai } \\
\text { dengan otori- } \\
\text { tas kewenan- } \\
\text { gannya }\end{array}$ & $\begin{array}{l}\text { Sistem menolak } \text { user } \\
\text { sistem akan me- } \\
\text { nolak jika di- } \\
\text { akses oleh } \\
\text { pengguna yang } \\
\text { tidak memiliki } \\
\text { hak akses pada } \\
\text { apses pada aplikasi, } \\
\text { halt u menjadi standar } \\
\text { keamanan pada apli- } \\
\text { kasi untuk menghin- }\end{array}$ & Vari penuplikasian \\
data & & \\
& & & & \\
\hline
\end{tabular}

Tabel 11. Pengujian Fungsional Indikator Compliance

\begin{tabular}{|l|l|l|l|l|}
\hline \multicolumn{1}{|c|}{ Fungsi } & \multicolumn{1}{|c|}{ Data Masukan } & \multicolumn{1}{|c|}{$\begin{array}{c}\text { Hasil yang } \\
\text { Diharapkan }\end{array}$} & $\begin{array}{c}\text { Pengama- } \\
\text { tan/Hasil Pen- } \\
\text { gujian }\end{array}$ & Keterangan \\
\hline Fungsi & Mengecek bebera- & Semua fungsi & Semua fungsi & valid \\
dari apli- & pa fungsional sis- & pada aplikasi & pada aplikasi & \\
kasi sis- & tem seperti : tam- & sesuai dengan & berjalan sesuai & \\
tem & bah data karyawan, & aturan sistem & $\begin{array}{c}\text { dengan aturan } \\
\text { sistem penggjian }\end{array}$ & \\
penggajia & pengubahan upah, & penggajian di & & \\
n data & melihat rekap lapo- & PT.AMM & & \\
karyawan & ran penggajian & & & \\
sesuai & & & & \\
\hline
\end{tabular}




\section{KESIMPULAN DAN SARAN}

\subsection{Kesimpulan}

Berdasarkan permasalahan yang muncul, maka untuk membuat suatu perencanaan sistem informasi penggajian menggunkan Zachman freamwork, ada hal-hal yang perlu diperhatikan perhatikan sebagai berikut:

1. Dengan adanya sistem penggajian ini maka proses absensi dan penggajian yang ada pada PT. AMM dapat dilakukan dengan lebih cepat danefektif.

2. Aplikasi yang dibangun ini akan memberikan kemudahan bagi pihak manajemen di mana proses perhitungan penggajian tidak perlu lagi dilakukan secaramanual.

3. Data absensi maupun data penggajian setiap karyawan akan tersimpan padadatabase.

\subsection{SARAN}

Untuk pengembangan lebih lanjut, diharapkan agar aplikasi absensi dan penjadwalan ini dapat digabungkan dengan sistem-sistem lainnya yang telah atau akan digunakan pada PT AMM.

\section{DAFTAR PUSTAKA}

[1] Undiksha.2017. Rancang Bangun Sistem Informasi Penggajian Karyawan. diakses pada tanggal 09 juni2019

[2] Richard Antonio Rompas, evaluasi efektifitas pengendalian intern sistem informasi akutansi pengajian RSUP. Prof.Dr.R.D Kandou Manado, 95115, Indonesia. Jurnal Riset Akuntansi Going Concern 13(2), 2018, 220-232

[3] FA arianta, 2012. "pengertian pengelolaan data" sir.stikom.edu

[4] Yuniarto, rahman Sistem informasi manajemen malang UB : 2003

[5] Wartika, Supriana, I., 2011, Analisis Perbandingan Komponen dan Karakteristik Enterprise Architecture Framework, Bali, Konfrensi National Sistem dan Informatika, KNS\&I 11-064.

[6] Setiawan, E., B., 2009, Pemilihan EA Framework, Yogyakarta, Prosiding SNATI, ISSN: 19075022.

[7] Widodo, A., P., 2010, Enterprise Architecture Model untuk Aplikasi Government, Jurnal Masyarakat Informatika, ISSN: 2086-4930.

[8] Brianorman, Y., Fiarni, C., 2011, Perancangan Enterprise Architecture Pada Puskesmas Yang Sesuai Untuk Penerapan Teknologi Cloud Computing, Bandung, Konfrensi Teknologi Informasi dan Komunikasi untuk Indonesia.

[9] Zachman, J.A. 2008. John Zachman's Concise Definition Of The Zachman Framework. Retrieved from:https://www.zachman.com/about-the-zachmanframework

[10] Surendro, K. 2009. Pengembangan Rencana Induk Sistem Informasi. Bandung: Penerbit Informatika.

[11] Whitten dan Bentley, System Analysis and Design Methods, 7, Newyork: McGraw-Hill, 2007: 371. 